\title{
EGFR mutations predict a favorable outcome for malignant pleural effusion of lung adenocarcinoma with Tarceva therapy
}

\author{
HAISHENG GUO $^{1 *}$, YUNYAN WAN ${ }^{1 *}$, GUANGYAN TIAN $^{2}$, QINGHUA LIU $^{1}$, \\ YANMENG KANG ${ }^{1}$, YUYE LI ${ }^{1}$, ZHOUHONG YAO ${ }^{1}$ and DIANJIE LIN ${ }^{1}$ \\ ${ }^{1}$ Department of Respiratory Medicine, Shandong Provincial Hospital, Shandong University, Jinan 250021; \\ ${ }^{2}$ Department of Neurology, Jinan Children's Hospital, Jinan 250022, P.R. China
}

Received September 21, 2011; Accepted November 9, 2011

DOI: $10.3892 /$ or.2011.1559

\begin{abstract}
The aim of the present study was to evaluate the therapeutic effects and adverse reactions of Tarceva treatment for malignant pleural effusion (MPE) caused by metastatic lung adenocarcinomas. One hundred and twenty-eight patients who failed first-line chemotherapy drug treatment were divided into a mutation and a non-mutation group according to the presence or absence of epidermal growth factor receptor (EGFR) mutations. Each patient received closed drainage combined with simple negative pressure suction after thoracoscopic talc poudrage pleurodesis and oral Tarceva treatment. Short-term and long-term clinical therapeutic effects of Tarceva were evaluated. The EGFR mutation rate in pleural metastatic tissues of lung adenocarcinoma acquired through video-assisted thoracoscopic surgery was higher compared to that in surgical resection specimens, plasma specimens and pleural effusion specimens compared to previously reported results. There were significant statistical differences in the average extubation time $(\mathrm{p}<0.01)$, drainage volume of pleural effusion $(\mathrm{p}<0.05)$, Karnofsky score and formation of encapsulated pleural effusion 4 weeks after surgery $(\mathrm{p}<0.05)$ between these two groups. The number of patients with mild pleural hypertrophy in the mutation group was significantly higher compared to the non-mutation group $(\mathrm{p}<0.01)$, while the number of patients with severe pleural hypertrophy was
\end{abstract}

Correspondence to: Dr Dianjie Lin, Department of Respiratory Medicine, Shandong Provincial Hospital, Shandong University, 324 Jing 7 Wei 5 Road, Jinan 250021, P.R. China

E-mail: lindianjie@126.com

*Contributed equally

Abbreviations: EGFR, epidermal growth factor receptor; MPE, malignant pleural effusion; VATS, video-assisted thoracoscopic surgery; PCR, polymerase chain reaction; NSCLC, non-small cell lung cancer; TKIs, tyrosine kinase inhibitors; WHO, World Health Organization; CR, complete remission; PR, partial remission; $\mathrm{NC}$, no change; PD, disease progression; TTP, thoracoscopic talc poudrage pleurodesis; ECG, electrocardiogram

Key words: Tarceva, EGFR mutation, malignant pleural effusion, follow-up, clinical efficacy significantly reduced $(\mathrm{p}<0.05)$. There was significant statistical discrepancy between these two groups in terms of improvement of peripheral blood carcinoembryonic antigen and tissue polypeptide antigen after 4 weeks of therapy. The complete remission rate and the efficacy rate were higher in the mutation group compared to that in the non-mutation group $(\mathrm{p}<0.05)$. There was a longer overall survival time after Tarceva treatment in patients with EGFR mutations than those without EGFR mutation. EGFR mutations predict a favorable outcome for malignant pleural effusion of lung adenocarcinoma with Tarceva therapy. Detection of EGFR mutations may determine the responsiveness of malignant pleural effusion to Tarceva treatment.

\section{Introduction}

Lung cancer ranks as the leading cause of cancer-related death among all malignant tumors (1). At a late stage of the disease, pleural metastasis and malignant pleural effusions (MPEs) are common. Although all cell types of lung cancer may cause MPEs, adenocarcinoma is the most common cell type (5). MPE is also a common complication of other advanced tumors such as breast cancer, lymphoma and mesothelioma. MPEs caused by breast and lung cancer account for approximately $75 \%$ of all cases (2-4).

At present, the treatments for MPEs include perfusion, surgery, radiotherapy and hyperthermia. Chest tube drainage and chemical pleurodesis are the standard care for malignant pleural effusions (6). Closed drainage with negative pressure suction helps to expel the residual gas and pleural effusion, adhere visceral and parietal pleural, and thus reduce the incidence of pleural hypertrophy and the formation of encapsulated pleural effusion (7).

Pleurodesis is an effective manner by which to treat malignant pleural effusion (8-10). In recent years, thoracoscopic talc poudrage pleurodesis (TTP) has been considered as an effective approach $(11,12)$. Closed drainage after thoracoscopic operation combined with negative pressure suction can dramatically shorten the drainage time and increase complete remission. Usually, application of the above method alone for MPEs is not sufficient, and chemotherapy drugs are needed. The optimal treatment for lung cancer patients who fail firstline chemotherapy is thus an important issue. 
In recent years, targeting of the epidermal growth factor receptor (EGFR) signaling pathway has become a focus of individualized therapy within the international oncology community. The clinical application of EGFR-targeted therapy for cancer patients has provided beneficial effects, and tyrosine kinase inhibitors (TKIs) have become important cancer treatment drugs.

Previous studies $(13,14)$ have shown that EGFR plays a critical role in cell proliferation, differentiation, metastasis and survival. Targeting of EGFR has had an effect on the prognosis of cancer patients.

The EGFR family includes the most representative molecules of the transmembrane-receptor-type tyrosine kinases with a wide range of biological functions. It plays important roles in growth, proliferation and differentiation of cells (16). The human EGFR family members including c-erbB-1 (HER1), c-erbB-2 (HER-2), c-erbB-3 (HER-3) and c-erbB-4 (HER-4) are located on the cell membrane. EGFR is a transmembrane glycoprotein $(170 \mathrm{kDa})$ encoded by oncogene c-erbB-1. It is composed of three parts, an extracellular domain, a transmembrane domain and an intracellular region which is composed of $621,23,542$ amino acid residues, respectively. The N-terminal extracellular region is a ligand binding domain of EGFR with high affinity (15).

EGFR and its natural ligands including epidermal growth factor (EGF), transforming growth factor (TGF), two-way adjustment factor, B cell growth factor and heparin-binding EGF are overexpressed in most non-small cell lung cancer (NSCLC) patients (5). Abnormal activation, amplification and overexpression of the EGFR gene were also found in lung adenocarcinoma. Pleural metastasis of lung adenocarcinoma was found to be closely related to EGFR $(5,13)$.

Ligands bind to the extracellular region of the receptor and activated receptor by inducing two neighboring receptor to form a dimer and further activate tyrosine kinase by autophosphorylation of tyrosine residues.

Activated HER-1/EGFR which combine with a multitude of different molecules in cells trigger various downstream signaling pathways, such as ras-raf-MEK-MAPK and PI3KPKC $-\kappa B$. Activated signaling pathways further activate transcription factors at the levels of transcription and translation. These transcription factors mediate a series of processes including cell differentiation, survival, migration, invasion, adhesion and cell damage repair (17).

Treatment techniques for malignant pleural effusion have greatly improved, yet no significant improvement in the survival rate and the quality of life of patients has been noted (18).

Iressa (gefitinib) and Tarceva (erlotinib) are the two main EGFR tyrosine kinase inhibitors (TKIs) used in the clinic $(19,20)$. Tarceva is the only one that possesses a survival advantage in treating lung cancer $(21,22)$. It is a new targeted therapy drug which can be selected after failed first- or second-line chemotherapy in patients with progressive and metastatic NSCLC (Tarceva received a certification license in the US in 2004 and in the European Union in 2005, respectively). Through specific inhibition of human EGFR tyrosine kinase activity and further inhibition of the EGFR downstream signaling pathway, Tarceva inhibits the growth of tumor cells by enhancing sensitivity to chemotherapy, promot- ting apoptosis, inhibiting proliferation, invasion, metastasis, angiogenesis and reducing adhesive ability (23).

However, not all patients with lung cancer have a favorable response to EGFR TKIs. In 2004, Lynch et al (24) and Paez et al (25) reported that EGFR mutations in lung cancer cells were a prerequisite for targeted drugs. That EGFR mutations are closely related to targeted therapy in NSCLC is widely recognized $(13,18,16-28)$.

Tarceva was found to be effective in $>80 \%$ of patients with EGFR mutations while it was largely ineffective in a non-mutation group (29-31). Thus, investigation of EGFR gene mutations in patients is necessary prior to using Tarceva. Currently, the best method for detecting EGFR mutations is through direct sequencing, Lynch et al (24) and Paez et al (25) were the first to report this method. This method accurately determines the scope and types of EGFR mutations. In this study, we applied this method to detect EGFR gene mutations.

Previous studies (30-33) have shown that lung cancer patients with an EGFR mutation have a favorable response to EGFR TKIs. However, the correlation between EGFR mutations in pleural metastatic tissues of lung adenocarcinoma and the therapeutic effect of Tarceva on MPE caused by metastatic lung adenocarcinoma remains uncertain. Questions concerning the association between the EGFR gene mutation and pleural metastasis tissues of lung adenocarcinoma; the therapeutic effects of Tarceva on malignant pleural effusion caused by metastatic lung adenocarcinoma; the relationship between EGFR mutations in pleural metastatic tissues of lung adenocarcinoma and the therapeutic effect of Tarceva on malignant pleural effusion caused by metastatic lung adenocarcinoma are still as yet unanswered. In this study, our aim was to systematically evaluate the relationship between the EGFR mutation in pleural metastasis tissues of lung adenocarcinoma and the therapeutic effect of Tarceva on malignant pleural effusion caused by metastatic lung adenocarcinoma.

\section{Materials and methods}

Patients and groups. The present study was approved by the Institutional Review Board of Shandong University, and requirement of informed consent was waived. Patients were enrolled at the Department of Respiratory Medicine and the Center of Cancer Treatment of Shandong Provincial Hospital, Chest Hospital, Shandong, China and the Central Hospital of Shengli Oil Field, Dongying, China from July, 2007 to August, 2009. A total number of 128 cases with malignant pleural effusion caused by metastatic lung adenocarcinoma diagnosed by thoracoscopic lung biopsy were recruited. The expected survival of these patients was longer than 3 months. All patients were divided into a mutation group and a nonmutation group according to the presence or absence of an EGFR mutation in pleural metastatic tissues of lung adenocarcinoma. The mutation group consisted of 90 cases including 48 males and 42 females with a mean age of $64.5 \pm 9.8$ years. The non-mutation group consisted of 38 cases including 20 males and 18 females with a mean age of $60.4 \pm 11.2$ years. Differences between the two groups were not significant, as shown in Table I.

All subjects were diagnosed by thoracoscopic lung biopsy, pathology or cytology. The patients were poorly responsive 
Table I. Clinical characteristics of the patients before treatment.

\begin{tabular}{|c|c|c|c|}
\hline Parameters & $\begin{array}{c}\text { Mutation group } \\
\mathrm{n}(\%)\end{array}$ & $\begin{array}{c}\text { Non-mutation group } \\
\mathrm{n}(\%)\end{array}$ & P-value \\
\hline Age (years) & & & 0.9681 \\
\hline$<50$ & $18(20.00)$ & $7(18.42)$ & \\
\hline $50-60$ & $29(32.22)$ & $12(31.58)$ & \\
\hline$>60$ & $43(47.78)$ & $19(50.00)$ & \\
\hline Gender & & & 0.9036 \\
\hline Male & $48(53.33)$ & $20(52.63)$ & \\
\hline Female & $42(46.67)$ & $18(47.37)$ & \\
\hline Smoking habit & & & 0.5372 \\
\hline Current & $16(17.78)$ & $7(18.42)$ & \\
\hline Former & $30(33.33)$ & $9(23.68)$ & \\
\hline Never & $44(48.89)$ & $22(57.89)$ & \\
\hline Grade & & & 0.9147 \\
\hline Well differentiated & $23(25.56)$ & $9(23.68)$ & \\
\hline Moderately differentiated & $32(35.56)$ & $15(39.47)$ & \\
\hline Poorly differentiated & 35 (38.89) & $14(36.84)$ & \\
\hline Karnofsky score & & & 0.9790 \\
\hline$<40$ & $18(20.00)$ & $7(18.42)$ & \\
\hline $40-70$ & $51(56.67)$ & $22(57.89)$ & \\
\hline$>70$ & $21(23.33)$ & $9(23.68)$ & \\
\hline
\end{tabular}

Based on statistical analysis, no significant statistical discrepancy in the clinical characteristics of the patients between the two groups prior to treatment was noted $(\mathrm{p}>0.05)$.

to radiotherapy and chemotherapy or exhibited toxicity for the chemotherapy drugs, and thus did not continue to receive first-line drugs such as docetaxel, gemcitabine, carboplatin or cisplatin.

Methods for specimen sampling and patient therapy. Preoperative examination for each patient included clotting time, ECG, as well as a chest X-ray for inspection of pleural adhesion. Artificial pneumothorax was created 1-2 days before surgery. Diazepam (10 mg) was injected intramuscularly one half hour before surgery.

Under conventional thoracoscopy, 4-5 spots in the pleural lesion tissues were taken for biopsy. These lesions were stored at $-80^{\circ} \mathrm{C}$ for pathological examination. Following biopsy, TTP was given to each patient. Medical sterilized talc powder was chosen as the sclerosing agent. We poudraged 2-4 g of talc powder to the pleural cavity uniformly under direct thoracoscope assistance after the injection of $50 \mathrm{mg}$ of pethidine (meperidine) intramuscularly. After TTP, each patient received closed drainage combined with simple negative pressure suction device to help expel the pleural effusion and gas in the thoracic cavity. Each patient was administered Tarceva chemotherapy in accordance with the scheduled treatment. Tarceva was taken orally at a dose of $150 \mathrm{mg}$ daily at $1 \mathrm{~h}$ before eating food or $2 \mathrm{~h}$ after eating food. After 4 weeks of treatment, we evaluated the short-term clinical therapeutic effects through imaging method such as CT and MRI. In order to observe the long-term therapeutic effects of Tarceva, each patient was followed up for one year. Peripheral blood ( $3 \mathrm{ml}$ ) of each patient was collected to detect CEA and TPA prior to and after 4 weeks of treatment.

The tubes were removed when the drainage volume of the pleural effusion was $<50 \mathrm{ml} /$ days. We reviewed the chest $\mathrm{X}$-ray examination and chest B-ultrasonic examination, and carried out Karnofsky scoring immediately after extubation and at 4 weeks after surgery. The patients without pleural effusion via B-ultrasonic examination were requested to receive anteroposterior chest X-ray to examine the extent of pleural hypertrophy. Complete remission (CR), partial remission (PR), no change (NC) and disease progression (PD) were determined according to the WHO criteria 4 weeks after surgery.

DNA extraction. DNA was extracted using the EZNA ${ }^{\mathrm{TM}}$ Tissue DNA kit (Shanghai Kenqiang Instrument Co., Ltd., Shanghai, China) from frozen tissues acquired from thoracoscopic biopsy.

DNA preparation. DNA extracted from frozen tissues was diluted 100 times with TE. A Nano Drop ${ }^{\circledR}$ (ND-1000) ultraviolet spectrophotometer was used to determine DNA concentration (Based on $1 \mathrm{OD}=50 \mu \mathrm{g} / \mathrm{ml}$ double-stranded nucleic acid the concentration of DNA samples was calculated) 
Table II. Primers of EGFR exons 18-21.

\begin{tabular}{ll}
\hline Exons & Primers \\
\hline 18 & F: 5'-GCTGAGGTGACCCTTGTCTC-3' \\
& R: 5'-ACAGCTTGCAAGGACTCTGG-3' \\
19 & F: 5'-GCAATATCAGCCTTAGGTGCGGTC-3' \\
& R: 5'-CATAGAAAGTGAACATTTAGGATGTG-3' \\
20 & F: 5'-CATTCATGCGTCTTCACCTG-3' \\
& R: 5'-CCGTATCTCCCTTCCCTGAT-3' \\
21 & F: 5'-CTAACGTTCGCCAGCCATAAGTCC-3' \\
& R: 5'-GCTGCGAGCTCACCCAGAATGTCTGG-3'
\end{tabular}

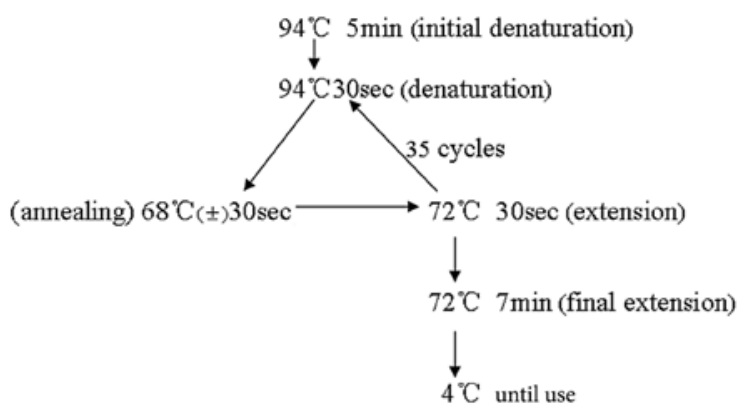

Figure 1. The PCR reaction conditions consisted of the following steps: initial denaturation at $94^{\circ} \mathrm{C}$ for $5 \mathrm{~min}, 35$ cycles of denaturation at $94^{\circ} \mathrm{C}$ for $30 \mathrm{sec}$, annealing at $68^{\circ} \mathrm{C}$ for $30 \mathrm{sec}$ for exons $18,19,20$ and 21 of the EGFR gene, and extension at $72^{\circ} \mathrm{C}$ for $30 \mathrm{sec}$, and a final extension step at $72^{\circ} \mathrm{C}$ for $7 \mathrm{~min}$, and stored at $4^{\circ} \mathrm{C}$ until used.

and purity (The ratio of OD260/OD280 was used to measure the purity of the extracted DNA). Test results: DNA purity, OD260/OD280=1.60-1.95; DNA concentration, 40-75 $\mathrm{ng} / \mu \mathrm{l}$. The extracted DNA was stored at $-20^{\circ} \mathrm{C}$ until its use.

PCR amplification and direct sequencing. According to a previously reported method (34), exons 18, 19, 20 and 21 of the EGFR gene were amplified by polymerase chain reaction (PCR). Primers used for amplification of exons 18-21 are showed in Table II Primers were synthesized by Shanghai Generay Biotech Co., Ltd., Shanghai. PCR was performed for 35 cycles in a programmable thermal cycler (Gene Amp PCR System 9600, Applied Biosystems, Foster City, CA, USA) with a volume of $50 \mu \mathrm{l}$ which contained $2 \mu \mathrm{l}$ of template DNA, $2 \mu \mathrm{l}$ of each primer $(10 \mu \mathrm{M}), 25 \mu \mathrm{l}$ of HotStarTaq Master Mix (Qiagen, product type: 203443; Merchant, Shanghai Pu Sheng Biotech Co., Ltd.) and $19 \mu \mathrm{l}$ of $\mathrm{dd}_{2} \mathrm{O}$. The PCR reaction conditions are shown in Fig. 1.

PCR products were directly sequenced in both sense and antisense directions in the ABI Prism 3100 Avant Genetic Analyzer. Only specimens in which a mutation was identified in both rounds were considered as mutation-positive. The nucleic acid and protein used to name the mutations were based on NG_007726.1 GI:188219609 (nucleotide) and NP_005219.2 GI:29725609 (amino acid) according to GenBank Accession, respectively.

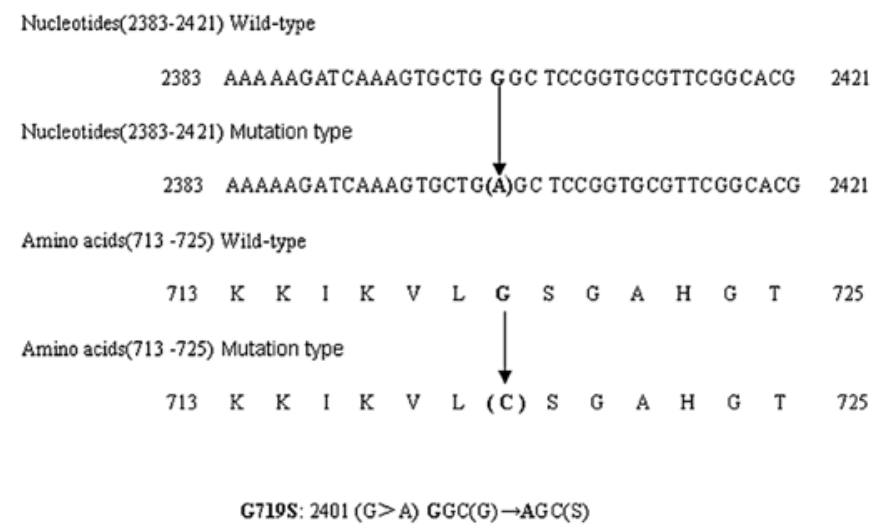

Figure 2. Site of the mutation in exon 18 of EGFR (G719S). The mutation was in codon 719 and appeared as a $\mathrm{G} \rightarrow \mathrm{A}$ transition, which resulted in glycine $(\mathrm{Gly}, \mathrm{G})$ to serine (Ser, S) amino acid mutation. [The nucleic acid and protein used to name the mutations were based on NG_007726.1 GI:188219609 (nucleotide) and NP_005219.2 GI:29725609 (amino acid) according to GenBank Accession, respectively].

Evaluation of the therapeutic effects. Therapeutic efficacy was evaluated for pleural effusion according to the WHO criteria as determined by chest X-ray (35), Karnofsky score (36) and the extent of pleura hypertrophy through chest X-ray (37).

Statistical analysis. Data are shown as the mean $\pm \mathrm{SD}$, using the SPSS16.0 software program. T-test, $\chi^{2}$ test and Fisher's exact test probability tests were used for statistics. $\mathrm{p}<0.05$ was considered to denote a significant difference. The log-rank test was used to compare progression-free survival and overall survival time. We calculated the total efficacy rate using CR+PR.

\section{Results}

Sequencing of EGFR exons 18-21. EGFR gene mutations were found in 90 of the 128 cases. The mutation rate was $70.31 \%$. The mutation types were missense mutation G719S in exon 18, L858R in exon 21 and in-frame mutation in exon 19.

G719S of exon 18 was detected in 5 patients $(3.90 \%)$. The mutation was in codon 719 and appeared to be a $\mathrm{G} \rightarrow \mathrm{A}$ transition, which results in a glycine $(\mathrm{Gly}, \mathrm{G})$ to serine (Ser, S) amino acid mutation (Fig. 2). Exon 19 mutations were detected in 56 cases, which accounted for $43.75 \%$ of the total number of patients.

The major mutations in exon 19 were the loss of codons from 746 to 750 (del E746-A750). There were 7 different mutations. Type I was a loss of 15 bases which resulted in a loss of EGFR protein 746-750 amino acids (ELREA). It is referred to here as del E746-A750 (I). Type II was characterized by the position of a base deletion which was shifted backward one base compared to type I. A loss of 15 bases was noted, but the lack of amino acids was the same as type I. Therefore, this type of mutation was termed del E746-A750 (II). Del E746A750 (I) and del E746-A750 (II) were the main types of EGFR mutations in exon 19 and were noted in a total of 35 cases, accounting for $27.34 \%$ of the total number of patients. Type III was characterized by a loss of nine bases, with a subsequent guanine $(\mathrm{G})$ conversion to cytosine $(\mathrm{C})$, which led to a 


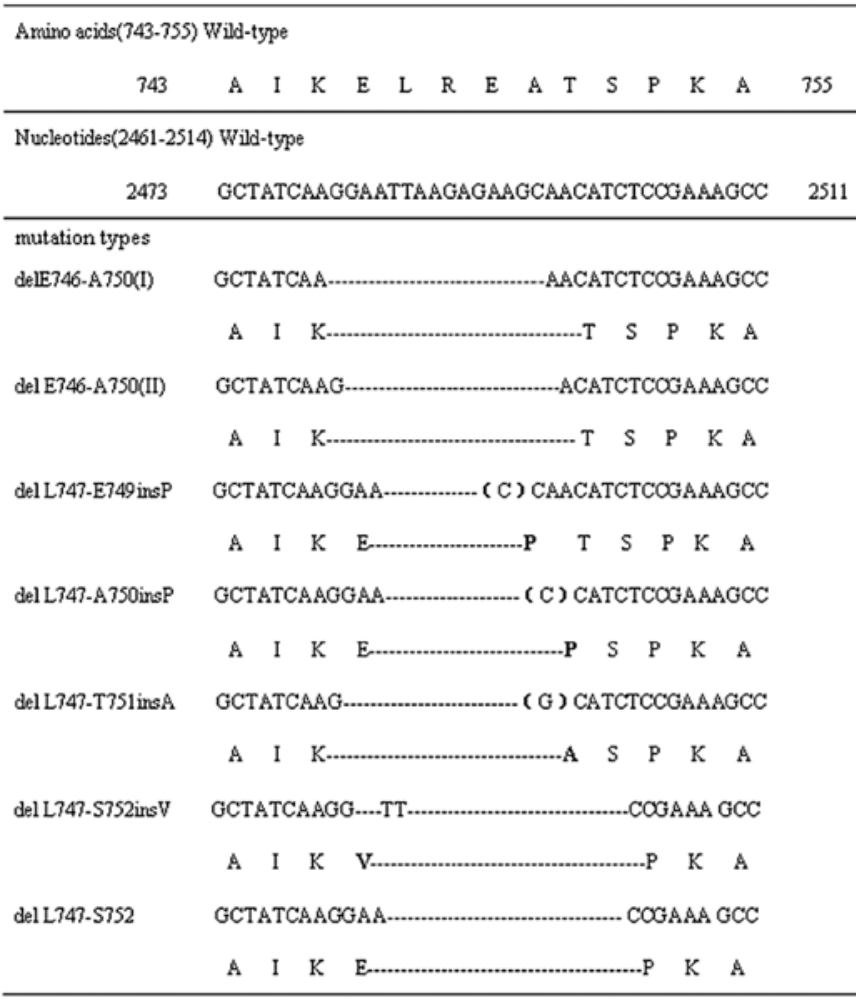

Figure 3. Sites of mutations in exon 19 of EGFR. Seven types of in-frame mutation in exon 19 were detected, from top to bottom as follows: del E746A750 (I), del E746-A750 (II), del L747-E749insP, del L747-A750insP, del L747-T751insA, del L747-S752insV and del L747-S752. [The nucleic acid and protein used to name the mutations were based on NG_007726.1 GI:188219609 (nucleotide) and NP_005219.2 GI:29725609 (amino acid) according to GenBank Accession, respectively].

loss of EGFR protein 747-749 amino acids (LRE), and at the same time introduced a new mutation, from alanine (A) to a proline (P). This type of mutation was termed del L747-E749insP. This mutation was detected in 6 patients, accounting for $4.69 \%$ of the total number of patients. Type IV included a loss of 13 bases, and the subsequent adenine (A) was converted to cytosine (C). This led to a loss of EGFR protein 747-750 amino acids (LREA), while introducing a new mutation from threonine $(\mathrm{T})$ into a proline $(\mathrm{P})$. This type of mutation was termed del L747-A750insP. This mutation occurred in 3 cases, accounting for $2.34 \%$ of the total number of patients. Type $\mathrm{V}$ was a 2482-2497 nucleotide deletion, resulting in an amino acid deletion (747 leucine to 751 threonine) and inserted alanine. This type of mutation was termed del L747-T751ins A. This mutation was found in 4 cases, accounting for $3.13 \%$ of the total number of patients. Type VI mutation was characterized by 2 base deletions (AA and AAGAGAAGCAACATCT) composition, resulting in the loss of EGFR protein 746-752 amino acids (LREATS), while introducing a new mutation with a change from glutamine (E) to valine $(\mathrm{V})$. This type of mutation was termed del E747-S752insV. This mutation was found in 5 patients, accounting for $3.91 \%$ of the total number of patients. Type VII included a loss in 18 bases, resulting in a loss of EGFR protein 747-752 amino acids (LREATS). This mutation was termed del L747-S752. This mutation was present in 3 cases, accounting for $2.34 \%$ of the total number of patients (Fig. 3).
Nucleotides(27941-2835) Wild-type

2794 CATGTCAAGATCACAGATTTTGGGC TGGCCAAACTGCTGGGT

2835

Nucleotides(27941-2835) Mutationtype

2794 CATGTCAAGATCACAGATTTTGGGC(G)G GCCAAACTGCTGGGT 2835

Amino acids(850-863) Wild-type

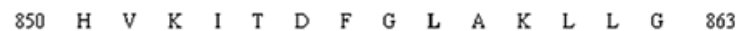

Amino acids(850-863) Mutationtype

$\begin{array}{lllllllllllllllll}850 & \text { H } & \text { V } & \text { K } & \text { I } & \text { T } & \text { D } & \text { F } & \text { G } & \text { R } & \text { A } & \text { K } & \text { L } & \text { L } & \text { G } & 863\end{array}$

LS58R: $\quad 2819(\mathrm{~T}>\mathrm{G}) \mathrm{CTG}(\mathrm{L}) \rightarrow \mathrm{CGG}(\mathrm{R})$

Figure 4. Site of the mutation in exon 21 of EGFR (L858R). The mutation $\mathrm{T} \rightarrow \mathrm{G}$ transition was in codon 858 , and caused a conversion from leucine (Leu, L) to arginine (Arg, R). [The nucleic acid and protein used to name the mutations were based on NG_007726.1 GI:188219609 (nucleotide) and NP_005219.2 GI:29725609 (amino acid) according to GenBank Accession respectively].

Table III. Correlation between EGFR mutations and clinical features.

\begin{tabular}{|c|c|c|c|c|c|}
\hline \multirow[b]{2}{*}{ Parameters } & \multicolumn{3}{|c|}{$\begin{array}{l}\text { Mutation in } \\
\text { exon }\end{array}$} & \multirow{2}{*}{$\begin{array}{c}\text { Mutation } \\
\text { rate }(\%)\end{array}$} & \multirow[b]{2}{*}{ p-value } \\
\hline & 18 & 19 & 21 & & \\
\hline Age (years) & & & & & 0.6483 \\
\hline$<50$ & 1 & 20 & 10 & 34.44 & \\
\hline $50-60$ & 1 & 17 & 8 & 28.89 & \\
\hline$>60$ & 3 & 19 & 11 & 36.67 & \\
\hline Gender (n) & & & & & 0.5271 \\
\hline Male & 2 & 31 & 15 & 53.33 & \\
\hline Female & 3 & 25 & 14 & 46.67 & \\
\hline Smoking (n) & & & & & 0.0033 \\
\hline Current & 0 & 16 & 5 & 23.33 & \\
\hline Former & 1 & 14 & 9 & 26.66 & \\
\hline Never & 4 & 26 & 15 & 50.00 & \\
\hline
\end{tabular}

EGFR mutations were detected more frequently in samples from nonsmokers than in current smokers and former smokers $(\mathrm{p}=0.0033)$. Age $(\mathrm{p}=0.6483)$ and gender $(\mathrm{p}=0.5271)$ were not associated with EGFR mutations.

L858R of exon 21 was detected in 29 patients, which accounted for $22.66 \%$ of all patients. This type of mutation was in codon 858 and appeared to be a $\mathrm{T} \rightarrow \mathrm{G}$ transition, resulting in conversion of leucine (Leu, L) to arginine (Arg, R) (Fig. 4).

Four patients carried both the del E746-A750 and L858R mutations. This type of mutation accounted for $3.13 \%$ of all patients. No mutations were detected in exon 20. In order to further verify the above results, these mutations were cloned and sequenced twice.

EGFR mutations were correlated with clinical features (Table III). EGFR mutations were detected more frequently in the samples from non-smokers than in current smokers and former smokers $(\mathrm{p}=0.0033)$. Age $(\mathrm{P}=0.6483)$ and gender $(\mathrm{p}=0.5271)$ were not associated with EGFR mutations. 
Table IV. Results of the clinical study.

\begin{tabular}{|c|c|c|c|}
\hline Parameters & Mutation group & Non-mutation group & $\mathrm{p}$-value \\
\hline Average extubation time (h) & $64.4 \pm 12.5$ & $144.2 \pm 15.4$ & $8.119 \times 10^{-36}$ \\
\hline Drainage volume $(\mathrm{ml})$ & $840.0 \pm 140.0$ & $1780.0 \pm 160.0$ & $7.011 \times 10^{-36}$ \\
\hline Formation of encapsulated pleural effusion (cases, \%) & $8(8.51)$ & $16(17.02)$ & $1.088 \times 10^{-5}$ \\
\hline \multicolumn{4}{|l|}{ Pleural hypertrophy (cases, \%) } \\
\hline Mild & $29(30.85)$ & $11(28.95)$ & 0.715 \\
\hline Moderate & $18(19.15)$ & $16(42.11)$ & 0.00968 \\
\hline Severe & $4(4.26)$ & $16(42.11)$ & $8.256 \times 10^{-8}$ \\
\hline
\end{tabular}

In the above table parameters, apart from the moderate pleural hypertrophy, there were significant statistical differences between the mutation group and non-mutation group $(\mathrm{p}<0.01)$.

Table V. Changes in Karnofsky score.

\begin{tabular}{|c|c|c|c|c|c|c|}
\hline \multirow[b]{2}{*}{ Groups } & \multirow[b]{2}{*}{ Total no. of patients } & \multicolumn{3}{|c|}{ Increase } & \multirow[b]{2}{*}{ No change } & \multirow[b]{2}{*}{ Decrease } \\
\hline & & 30 & 20 & 10 & & \\
\hline Mutation group (cases, \%) & 90 & $13(14.44)$ & $34(37.78)$ & $20(22.22)$ & $13(14.44)$ & $10(11.11)$ \\
\hline Non-mutation group (cases, \%) & 38 & 1 (2.63) & $11(28.95)$ & $10(26.32)$ & $5(13.16)$ & $11(28.95)$ \\
\hline p-value & & 0.0304 & 0.4512 & 0.7863 & 0.9307 & 0.0259 \\
\hline
\end{tabular}

The increase in the ratio of 30 points in the mutation group was significantly higher than that in the non-mutation group. The decrease in the ratio of the Karnofsky score in the mutation group was significantly lower than that in the non-mutation group. There was a significant statistical difference in the above parameters between the two groups $(\mathrm{p}<0.05)$; there was no statistical difference in other parameters between the two groups $(\mathrm{p}>0.05)$.

Table VI. Comparison of the clinical efficacy.

\begin{tabular}{|c|c|c|c|c|c|c|}
\hline \multirow[b]{2}{*}{ Group } & \multirow[b]{2}{*}{ Total no. of patients } & \multicolumn{3}{|c|}{$\begin{array}{c}\text { Efficacy } \\
\text { (no. of patients) }\end{array}$} & \multirow{2}{*}{$\begin{array}{c}\text { CR rate }(\%) \\
(\mathrm{CR} / \text { total no. of cases })\end{array}$} & \multirow{2}{*}{$\begin{array}{c}\text { Efficacy rate }(\%) \\
(\mathrm{CR}+\mathrm{PR} / \text { total no. of patients })\end{array}$} \\
\hline & & CR & PR & $\mathrm{NC}$ & & \\
\hline Mutation group & 90 & 55 & 20 & 15 & 61.11 & 83.33 \\
\hline Non-mutation group & 38 & 17 & 9 & 12 & 44.74 & 68.42 \\
\hline p-value & & & & & 0.02945 & 0.02151 \\
\hline
\end{tabular}

$\mathrm{CR}$, complete remission; PR, partial remission; NC, no change.

Clinical study results. The average extubation time in the mutation group $(64.4 \pm 12.5 \mathrm{~h})$ was shorter than that of the non-mutation group $(144.2 \pm 15.4 \mathrm{~h})(\mathrm{p}<0.01)$ (Table IV). The drainage volume of pleural effusion in the mutation group was $840 \pm 140 \mathrm{ml}$ and in the non-mutation group was $1780 \pm 160 \mathrm{ml}(\mathrm{p}<0.01)$. Four weeks after surgery, 8 patients in the mutation group and 16 patients in the non-mutation group were found with formation of encapsulated pleural effusion $(\mathrm{p}<0.01)$. The number of the patients with mild, moderate and severe pleural hypertrophy were 29,18 and 4 in the mutation group and 11, 16 and 16 in the non-mutation group, respectively. The number of patients with mild pleural hypertrophy in the mutation group was significantly higher than that in the non-mutation group $(\mathrm{p}<0.01)$, while the number of patients with severe pleural hypertrophy was significantly reduced $(\mathrm{p}<0.01)$ (Table IV).

Changes in Karnofsky score. Four weeks after surgery, the Karnofsky score was increased by 30 in 13 patients in the mutation group (14.44\%), while this increase was noted in only 1 patient in the non-mutation group (2.63\%) (Table V). The Karnofsky score was increased by 20 in 34 patients in the mutation group $(37.78 \%)$, while this increase was noted in only 11 patients in the non-mutation group (28.95\%). The 
Table VII. Changes in CEA and TPA in peripheral blood after one month of treatment.

\begin{tabular}{llccc}
\hline Parameters & \multicolumn{1}{c}{ Groups } & Before treatment & After one month of treatment & p-value \\
\hline CEA $(\mu \mathrm{g} / \mathrm{l})$ & Mutation group & $101.2 \pm 42.5$ & $14.6 \pm 6.5$ & \\
& Non-mutation group & $98.8 \pm 50.4$ & $84.5 \pm 7.8$ & 0.009158 \\
\multirow{2}{*}{ TPA $(\mu \mathrm{g} / \mathrm{l})$} & Mutation group & $7.6 \pm 1.4$ & $1.4 \pm 0.3$ & \\
& Non-mutation group & $8.2 \pm 1.2$ & $7.8 \pm 1.5$ & 0.049836 \\
\hline
\end{tabular}

CEA, carcinoembryonic antigen; TPA, tissue polypeptide antigen.

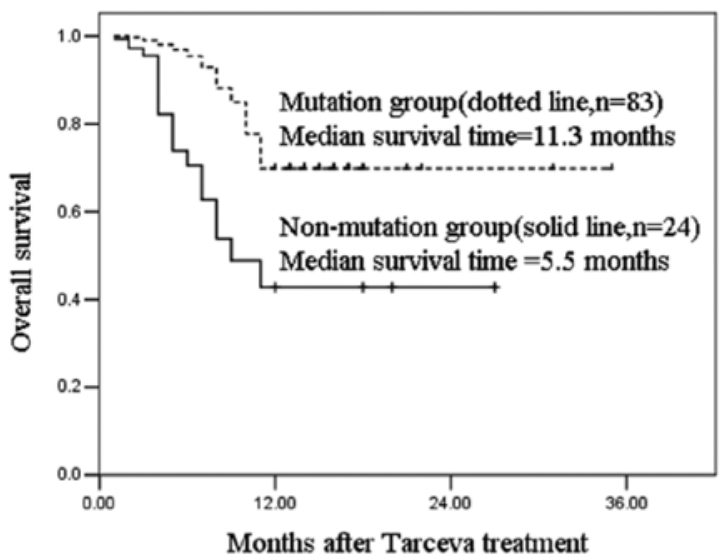

Figure 5. Comparison of overall survival time between the mutation group (dotted line) and the non-mutation group (solid line). Kaplan-Meier survival curve showed that the overall survival was significantly improved in the EGFR mutation group $(\mathrm{p}<0.001$ by log-rank test).

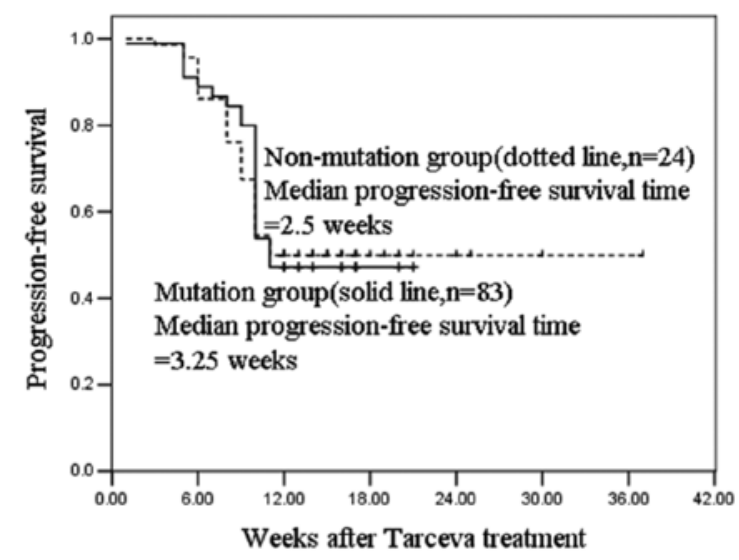

Figure 6. Comparison of progression-free survival time between the mutation group (solid line) and the non-mutation group (dotted line), Kaplan-Meier survival curve showed that there was no significant difference in progressionfree survival time between these two groups ( $\mathrm{p}=0.93$ by log-rank test).

Karnofsky score was decreased in 11 patients in the non-mutation group (28.95\%), while this decrease was noted in only 10 patients in the mutation group (11.11\%). These differences were statistically significant $(\mathrm{p}<0.05)$. However, there was no significant statistical difference in patients whose Karnofsky score increased by 10 and no change between these two groups was noted ( $p>0.05)$. Taken together, these data suggest that the quality of life of the patients in the mutation group was significantly improved than that in the non-mutation group with the combined therapy (Table V).

Comparison of clinical efficacy. Comparing the two groups in clinical efficacy, the CR rate and efficacy rate were 61.11 and $83.33 \%$ respectively in the mutation group, which were significantly higher than these values (CR rate, $44.74 \%$; efficacy rate, $68.42 \%$ ) in the non-mutation group, which showed a significant statistical discrepancy $(\mathrm{p}<0.05)($ Table VI).

Changes in CEA and TPA in peripheral blood extracted from each patient before treatment and after one month of treatment. Electrochemical luminescence was applied to test serum CEA and TPA of all patients before receiving Tarceva and one month after treatment, respectively. CEA and TPA in peripheral blood decreased gradually, but the degree of decrease was higher in the mutation group than that in the non-mutation group. Based on the statistical analysis, a significant statistical difference was achieved between the two groups ( $p$-value $<0.05)$ (Table VII).

Results of the patient follow-up. Patients enrolled in this study were followed up for one year. During this period, 9 patients were lost in the follow-up ( 2 cases in the mutation group; 7 cases in the non-mutation group). Twelve patients (5 cases in the mutation group; 7 cases in the non-mutation group) discontined treatment due to moderate or severe liver and renal dysfunction.

Fifty-six patients died in the mutation group and 18 patients died in the non-mutation group. One-year survival rate was $32.53 \%$ in the mutation group and $25.00 \%$ in the non-mutation group.

The median progression-free survival time and the median overall survival time were 3.25 and 11.30 months in the mutation group and 2.50 and 5.50 months in the non-mutation group, respectively. The overall survival was significantly improved in the mutation group $(\mathrm{p}<0.001$ by log-rank test) (Fig. 5). However, there was no significant difference in progression-free survival time between these two groups ( $\mathrm{p}=0.93$ by $\log$-rank test) (Fig. 6).

Adverse reactions during Tarceva treatment. In the course of treatment, different types and different levels of side effects occurred. The main adverse responses are shown in Table VIII. 
Table VIII. Main adverse reactions of all patients.

\begin{tabular}{lcrc}
\hline Parameters & Mutation group & Non-mutation group & p-value \\
\hline Fever (days) & $3.2 \pm 1.2$ & $2.8 \pm 1.6$ & 0.1715 \\
Chest pain (cases, \%) & $46(51.11)$ & $23(60.53)$ & 0.3289 \\
Rash (cases, \%) & $62(68.89)$ & $9(23.68)$ & $2.583 \times 10^{-6}$ \\
Diarrhea (cases, \%) & $24(26.67)$ & $14(36.84)$ & 0.2496 \\
Anorexia (cases, \%) & $22(24.44)$ & $16(42.11)$ & 0.4152 \\
Moderate and severe liver dysfunction (cases, \%) & $6(6.67)$ & $2(5.26)$ & 0.7640 \\
Moderate and severe renal dysfunction (cases, \%) & $3(3.33)$ & $1(2.63)$ & 0.8350 \\
\hline
\end{tabular}

For the above table parameters, apart from rash $(\mathrm{p}<0.01)$, no significant statistical differences were achieved between the mutation and nonmutation group $(\mathrm{p}>0.01)$.

Twenty-four patients had fever for 2-5 days in the mutation group, of whom the temperature of 4 patients was $>39^{\circ} \mathrm{C}$, and the average duration of fever was $3.2 \pm 1.2$ days. In contrast, 27 patients had fever for 2-5 days in the non-mutation group, of whom the temperature of 3 patients was $>39^{\circ} \mathrm{C}$, and the average duration of fever was $2.8 \pm 1.6$ days. Forty-six patients presented with chest pain in the mutation group, while 23 patients presented with chest pain in the non-mutation group. The differences were not significant between these two groups ( $p>0.05$ ).

After 7-10 days of treatment, rash occured in 62 cases $(68.89 \%)$ with EGFR mutations and 9 cases $(23.68 \%)$ without EGFR mutations. The difference was statistically significant $(\mathrm{p}<0.05)$. These rashs disappeared a few days after clindamycin treatment.

Mild diarrhea and anorexia were also observed in the two groups ( $p>0.05)$. No special treatments were required for these symptoms. Several patients experienced moderate to severe liver and renal dysfunction. After stopping Tarceva treatment, liver and renal functions gradually returned to normal. There were no other significant adverse reactions.

\section{Discussion}

In this study, EGFR mutations were examined in pleural metastatic tissues of lung adenocarcinoma biopsied through video-assisted thoracoscopic surgery (VATS) by PCR amplification and direct sequencing. The therapeutic effects of Tarceva on MPEs were compared between the EGFR mutation and non-mutation group.

DNA sequencing is the gold-standard method for detection of mutations. In this study, we applied this gold-standard method to detect EGFR mutations in pleural metastatic tissues of lung adenocarcinoma acquired through VATS. This procedure included four steps: firstly, we acquired lesion tissues through VATS; secondly, the histopathological type of the acquired lesion tissue was determined; thirdly, DNA was extracted and amplified by PCR; and fourthly EGFR mutations were detected by direct sequencing.

It was well known that EGFR mutations are frequently observed in lung adenocarcinomas. Soh et al (38) and Gow et al (39) reported an EGFR mutation rate of $24.5 \%$ (13 out of
53) in MPEs of lung adenocarcinoma. Kimura et al (40) found a $13 \%$ (3 out of 23) EGFR mutation rate by direct sequencing of EGFR mutations in MPEs of lung adenocarcinoma, of which $9.1 \%$ ( 1 out of 11 ) were females and $10 \%$ (1 out of 10 ) were never smokers. Overall, the EGFR mutation rate of MPEs ranged from 9.1 to $68.4 \%$. This variability probably reflects the methodology, selection of patients, and geographic differences. The incidence of EGFR mutations in NSCLC ranged from 10 to $50 \%(34,41-45)$.

In the present study, EGFR mutations were detected in 90 of the 128 patients with pleural metastasis of lung adenocarcinoma. The EGFR mutation rate was $70.31 \%$. There were 5 missense mutations in exon 18, 56 in frame deletion mutations in exon 19 and 29 missense mutations in exon 21, which accounted for $3.90,43.75$ and $22.66 \%$ of the total number of patients, respectively. Four patients carried both del E746A750 and L858R mutations. This type of mutation accounted for $3.13 \%$ of the total number of patients. No mutations were detected in exon 20. The EGFR mutations found in this study (43.75\% in exon $19,22.66 \%$ in exon 21 ) were consistent with previous findings $(20,24,25,28,30,46)$.

Jian et al (47) used free DNA from plasma and pleural effusion to detect EGFR mutations by PCR using Taqman-MGB probes. The EGFR mutation rate was $23.2 \%$ in 56 plasma samples and $28.1 \%$ in 32 pleural effusion samples. The EGFR mutation rate was $31.9 \%$ in 69 patients with lung adenocarcinoma. In our study, the EGFR mutation rate was $70.31 \%$, which was much higher than the above results. Wu et al (48) detected EGFR mutations in surgical resected specimens of lung adenocarcinoma. The results showed that 93 out of 136 patients with MPEs caused by lung adenocarcinoma had positive EGFR mutations. The mutation rate was $68.4 \%$, which was close to our findings $(70.31 \%)$. These findings showed that the EGFR mutation rate detected in lesion tissues was much higher than that in plasma and pleural effusion samples indicating that there were more false-negative results in plasma and pleural effusion samples.

It has been reported that EGFR mutations occured more frequently in female patients and never smokers $(49,50)$. Yang (32) reported that the EGFR mutation rate was significantly higher in adenocarcinoma than in other types of NSCLC (21 
vs. $2 \%$ ), higher in females than in males (20 vs. $9 \%$ ), and higher in Asian patients than in European and American patients (26 vs. $2 \%$ ). In another report, Huang et al (45) showed that the EGFR mutation rate in resected lung adenocarcinoma was not associated with gender (females vs. males, 54.5 vs. $55.5 \%$ ) and smoking history in Taiwan. In our study, EGFR mutations were detected more frequently in non-smoking patients $(50.00 \%$ in non-smokers, $23.33 \%$ in current smokers and $26.66 \%$ in former smokers respectively, $\mathrm{p}=0.0033)$. However, EGFR mutations were not closely related to age $(p=0.6483)$ and gender $(\mathrm{p}=0.5271)$. The reasons for the differences between these studies are unclear.

In recent years, many studies $(24,25,51-53)$ have reported that the clinical therapeutic effects of TKIs are closely associated with EGFR mutations in NSCLC patients. In a clinical study by Shepherd et al (54), 731 patients with NSCLC were randomly treated with oral Tarceva $(150 \mathrm{mg} /$ day $)$ and a placebo at the ratio of 2:1 until the ocurrence of disease progression or unacceptable toxicity. The results showed that Tarceva significantly prolonged the survival time of patients with advanced NSCLC. The median survival time increased by $42.5 \%$ when compared to the control group (6.7 vs 4.7 months). The 1-year survival rate increased by $45 \%$ compared with the control group (31.2 vs. $21.5 \%)$. The median progression-free survival (PFS) was 9.7 weeks in the treatment group and 8.0 weeks in the placebo group ( $\mathrm{HR}=0.61, \mathrm{p}<0.001)$. Tarceva was the only EGFR TKI confirmed by the test that may improve the progression-free survival (PFS) of patients.

TTP combined with closed drainage and simple negative pressure suction is an effective therapy for malignant and refractory benign pleural effusions (55-57). In our study, TTP was applied through VATS and then closed thoracic drainage combined with simple negative pressure suction was administered to each patient. TTP applied through VATS had several advantages: i) pleural effusions could be fully suctioned under direct vision assisted by thoracoscope; ii) pleura was better exposed via releasing the pleural adhesion which ensured the accuracy and reliability of specimen sampling; iii) talc powder could be distributed uniformly on both visceral and parietal pleura; iv) closed drainage after thoracoscopic operation with the addition of negative pressure suction could help expel the residual gas and pleural effusion caused by tumor infiltration or stimulation of pleurodesis agent. Thus, the visceral and parietal pleural could adhere closely which would reduce the incidence of pleural hypertrophy and the formation of encapsulated pleural effusion. This may result in a synergistic effect with Tarceva. After one month of treatment, the clinical therapeutic results showed that average extubation time was significantly shorter and drainage volume was significantly less in the mutation group compared with that in the nonmutation group. Formation of encapsulated pleural effusion in the non-mutation group was significantly more than that in the mutation group. The number of cases forming severe pleural hypertrophy in the non-mutation group was significantly higher than that in the mutation group.

The Karnofsky score in patients varied significantly. From the changes in Karnofsky score, we determined that the improvement in the quality of life of the patients with an EGFR mutation was obviously better than that of the patients without mutations.
CEA is a broad spectrum tumor marker that reflects the existence of a variety of tumors, such as colorectal, breast and lung cancer. It is also a good tumor marker to determine efficacy of treatment, disease progression and prognosis. Serum TPA is a non-specific tumor marker which is closely related to cell proliferation. Serum TPA increases during the division and proliferation of tumor cells and thus it is commonly used in the diagnosis of malignant tumors. TPA in blood decreases to normal levels indicating that the treatment for cancer was effective. In our study, peripheral blood CEA and TPA in the mutation group gradually returned to normal one month after treatment. These parameters also slightly decreased in the nonmutation group. These results suggest that the clinical efficacy of Tarceva for MPEs in the mutation group was significantly better than that in the non-mutation group.

According to the WHO criteria of treatment for pleural effusion, 4 weeks after surgery, the CR and efficacy rates (CR+PR/total no. of patients) were 61.11 and $83.33 \%$, respectively, in the mutation group, which were significantly higher than that (CR rate, $44.74 \%$; efficacy rate, $68.42 \%$ ) in the nonmutation group $(\mathrm{p}<0.05)$.

After the one-year follow-up, we found that the EGFR mutation is a prognostic factor for progression-free survival time and overall survival time. Patients with an EGFR mutation have a longer median overall survival time (11.30 vs. 5.50 months) than patients without an EGFR mutation. Overall survival was significantly improved in the mutation group ( $\mathrm{p}<0.001$ by log-rank test) (Fig. 5). Patients with an EGFR mutation also had a longer median progression-free survival time (3.25 vs. 2.50 months). However, the difference in progression-free survival time between the two groups was not significant ( $\mathrm{p}=0.93$ by log-rank test) (Fig. 6).

The 1-year survival rate was $32.53 \%$ in the mutation group vs. $25.00 \%$ in the non-mutation group. The above rates were equivalent to the reported literature $(24,25,58-60)$.

In the course of treatment, side effects observed included rash, diarrhea, liver dysfunction and renal dysfunction. The incidence of rash was $34.04 \%$ in the mutation group and 5.32\% in the non-mutation group. There was a significant statistical discrepancy between the two groups. The severity of rash was correlated with better clinical efficacy.

There were several limitations in this study. For example, geographic (ethnic) differences in detection of the EGFR mutation may result in variability. The results of previous studies $(30,34,42,61-66)$ showed that there were significant differences in the sites and main types of EGFR mutations in different races and regions. Most of the specimens in this study came from Shandong, China. Thus, conclusions from our study might not be representative of other regions. On the other hand, methods for detecting EGFR mutations and pathological types of lung cancer may account for the differences found in EGFR gene mutations. An extensive nation-wide clinical trial may be able to solve some of these issues.

In conclusion, our results suggest that there was a higher EGFR mutation rate in pleural metastatic tissues of lung adenocarcinoma obtained by VATS than that in the surgically resected specimens, plasma specimens and pleural effusion specimens. The therapeutic effects of Tarceva for malignant pleural effusion caused by metastatic lung adenocarcinoma was closely related to EGFR mutations of pleural metastatic tissues. 
There was a longer overall survival time after Tarceva treatment for those patients with EGFR mutations than those without EGFR mutations. Although there was a longer progression-free survival time, after analysis of medical statistics, there were no significant differences between the two groups.

\section{Acknowledgements}

We thank the medical staff at the Department of Respiratory Medicine, The Center for Cancer Treatment of Shandong Provincial Hospital, at the Chest Hospital and at the Department of Respiratory of Central Hospital, Shengli Oil Field, Dongying, China for their support. We also thank Weixia Ma and other physicians in the Thoracoscopic Division for their help with simple negative pressure suction and thoracoscopic talc pleurodesis.

\section{References}

1. Ferlay J, Parkin DM and Steliarova-Foucher E: Estimates of cancer incidence and mortality in Europe in 2008. Eur J Cancer 46: 765-781, 2010.

2. Lynch TJ: Management of pleural effusions. Chest 103 (Suppl 4): 385-389, 1993.

3. Stefani A, Natali P, Casali C and Morandi U: Talc poudrage versus talc slurry in the treatment of malignant pleural effusion. A prospective comparative study. Eur J Cardiothorac Surg 30: 827-832, 2006.

4. Debeljak A, Keceli P, Triller N, Letonja S, Kern I, Debevec L and Rozman A: Talc pleurodesis: comparison of talc slurry instillation with thoracoscopic talc insufflation for malignant pleural effusions. J BUON 11: 463-467, 2006.

5. Harley H: Malignant pleural effusion. Thorax 31: 485, 1976.

6. Barbetakis N, Asteriou C, Papadopoulou F, et al: Early and late morbidity and mortality and life expectancy following thoracoscopic talc insufflation for control of malignant pleural effusions: a review of 400 cases. J Cardiothorac Surg 19: 27, 2010.

7. Lin $\mathrm{D}$, Teng $\mathrm{W}$ and $\mathrm{Wu} \mathrm{M}$ : Preliminary observations of the treatment of pneumothorax by simple negative pressure suction. J Practical Pulmonary 3: 48-49, 1997.

8. Koischmann S, Ballin A, Juergens UR, Rohde G, Gessner C, Hammmmerschmidt S, Wirtz $\mathrm{H}$ and Gillissen A: Talc pleurodesis in malignant pleural effusions. Pneumologie 60: 89-95, 2006.

9. Pletinckx P, Muysoms F, De Decker C, Daeter E and Claeys D: Thoracoscopic talc pleurodesis for the treatment of spontaneous pneumothorax. Acta Chir Belq 105: 504-507, 2005.

10. Koischmann S, Ballin A and Gillissen A: Clinnical efficacy and safety of thoracoscopic talc pleurodesis in malignant pleural effusions. Chest 12: 1431-1435, 2005.

11. Aelony Y and Yao JF: Prolonged survival after talc poudrage for malignant pleural mesothelioma: case series. Respirology 10: $649-655,2005$.

12. Mourad IA, Abdel Rahman AR, Aziz SA, Saber NM and Fouad FA: Pleurodesis as a palliative treatment of advanced lung cancer with malignant pleural effusion. J Egypt Natl Cancer Inst 16: 188-194, 2004.

13. Scagliotti GV, Selvaggi G, Novello S and Hirsch FR: The biology of epidermal growth factor receptor in lung cancer. Clin Cancer Res 10: 4227-4232, 2004.

14. Franklin WA, Veve R, Hirsch FR, Helfrich BA and Bunn PA Jr: Epidermal growth factor receptor family in lung cancer and premalignancy. Semin Oncol 29 (1 Suppl 4): 3-14, 2002.

15. Davies RL, Grosse VA, Kucherlapati R and Bothwell M: Genetic analysis of epidermal growth factor action: assignment of human epidermal growth factor receptor gene to chromosome 7. Proc Natl Acad Sci USA 77: 4188-4192, 1980.

16. Roskoski R Jr: The ErbB/HER receptor protein tyrosine kinases and cancer. Biochem Biophys Res Commun 319: 1-11, 2004.

17. Jorissen RN, Walker F, Pouliot N, Garrett TP, Ward CW and Burgess AW: Epidermal growth factor receptor: mechanisms of activation and signalling. Exp Cell Res 284: 31-53, 2003.

18. Parkin DM, Bray Fl and Devesa SS: Cancer burden in the year 2000. The global picture. Eur J Cancer 37 (Suppl 8): S4-S66, 2001.
19. Mitsudomi T: Small-molecule tyrosine kinase inhibitors of epidermal growth factor receptor (EGFR). Gan To Kaqaku Ryoho 36: 1058-1062, 2009.

20. Varella-Garcia M, Mitsudomi T, Yatabe Y,Kosaka T, Nakajima E, Xavier AC, Skokan M, Zeng C, Franklin WA, Bunn PA Jr and Hirsch FR: EGFR and HER2 genomic gain in recurrent non-small cell lung cancer after surgery: impact on outcome to treatment with gefitinib and association with EGFR and KRAS mutations in a Japanese cohort. J Thorac Oncol 4: 318-325, 2009.

21. Costa DB, Nguyen KS, Cho BC, Sequist LV, Jackman DM, Riely GJ, Yeap BY, Halmos B, Kim JH, Janne PA, Huberman MS, Pao W, Tenen DG and Kobayashi S: Effects of erlotinib in EGFR mutated non-small cell lung cancers with resistance to gefitinib. Clin Cancer Res 14: 7060-7067, 2008.

22. Wong AS, Soong R, Seah SB, Lim SW, Chuah KL, Nga ME, Chin TM and Soo RA: Evidence for disease control with erlotinib after gefitinib failure in typical gefitinib-sensitive Asian patients with non-small cell lung cancer. J Thorac Oncol 3: 400-404, 2008.

23. Bergot E, Richard N and Zalcman G: Mechanisms of action of targeted therapies... and mechanisms of resistance. Rev Mal Respir 24: 65180-65187, 2007.

24. Lynch TJ, Bell DW, Sordella R, Gurubhagavatula S, Okimoto RA, Brannigan BW, Harris PL, Haserlat SM, Supko JG, Haluska FG, Louis DN, Christiani DC, Settleman J and Haber DA: Activating mutations in the epidermal growth factor receptor underlying responsiveness of non-small cell lung cancer to gefitinib. N Engl J Med 350: 2129-2139, 2004

25. Paez JG, Janne PA, Lee JC, Tracy S, Greulich H, Gabriel S, Herman P, Kaye FJ, Lindeman N, Boggon TJ, Naoki K, Sasaki H, Fujii Y, Eck MJ, Sellers WR, Johnson BE and Meyerson M: EGFR mutations in lung cancer: correlation with clinical response to gefitinib therapy. Science 304: 1497-1500, 2004.

26. Ansari J, Palmer DH, Rea DW and Hussain SA: Role of tyrosine kinase inhibitors in lung cancer. Anticancer Agents Med Chem 9: 569-575, 2009.

27. Linardou H, Dahabreh IJ, Bafaloukos D, Kosmidis P and Murray S: Somatic EGFR mutations and efficacy of tyrosine kinase inhibitors in NSCLC. Nat Rev Clin Oncol 6: 352-366, 2009.

28. Carlson JJ, Garrison LP, Ramsey SD and Veenstra DL: Epidermal growth factor receptor genomic variation in NSCLC patients receiving tyrosine kinase inhibitor therapy: a systematic review and meta-analysis. J Cancer Res Clin Oncol 135: 1483-1493, 2009.

29. Sartori G, Cavazza A, Sgambato A, Marchioni A, Barbieri F, Longo L, Bavieri M, Murer B, Meschiari E, Tamberi S, Cadioli A, Luppi F, Migaldi M and Rossi G: EGFR and K-ras mutations along the spectrum of pulmonary epithelial tumors of the lung and elaboration of a combined clinicopathologic and molecular scoring system to predict clinical responsiveness to EGFR inhibitors. Am J Clin Pathol 131: 478-489, 2009.

30. Kosaka T, Yatabe Y, Endoh H, Kuwano H, Takahashi T and Mitsudomi T: Mutations of the epidermal growth factor receptor gene in lung cancer: biological and clinical implications. Cancer Res 64: 8919-8923, 2004.

31. Zakowski MF, Hussain S, Pao W, Ladanyi M, Ginsberg MS, Heelan R, Miller VA, Rusch VW and Kris MG: Morphologic features of adenocarcinoma of the lung predictive of response to the epidermal growth factor receptor kinase inhibitors erlotinib and gefitinib. Arch Pathol Lab Med 133: 470-477, 2009.

32. Yang $\mathrm{CH}$ : EGFR tyrosine kinase inhibitors for the treatment of NSCLC in East Asia: present and future. Lung Cancer 60 (Suppl 2): 23-30, 2008.

33. Murray S, Dahabreh IJ, Linardou H, Manoloukos M, Bafaloukos D and Kosmidis P: Somatic mutations of the tyrosine kinase domain of epidermal growth factor receptor and tyrosine kinase inhibitor response to TKIs in non-small cell lung cancer: an analytical database. J Thorac Oncol 3: 832-839, 2008.

34. Tomizawa Y, Iijima H, Sunaga N, Sato K, Takise A, Otani Y, Tanaka S, Suga T, Saito R, Ishizuka T, Dobashi K, Minna JD, Nakajima T and Mori M: Clinicopathologic significance of the mutations of the epidermal growth factor receptor gene in patients with non-small cell lung cancer. Clin Cancer Res 11: 6816-6822, 2005.

35. Millar JW, Hunter AM and Horne NW: Intrapleural immunotherapy with Corynebacterium parvum in recurrent malignant pleural effusions. Thorax 35: 856-858, 1980.

36. Mor V, Laliberte L, Morris JN and Wiemann M: The Karnofsky Performance Status Scale. An examination of its reliability and validity in a research setting. Cancer 53: 2002-2007, 1984. 
37. Hierholzer J, Luo L, Bittner RC, et al: MRI and CT in the differential diagnosis of pleural disease. Chest 118: 604-609, 2000.

38. Soh J, Toyooka S and Aoe K: Usefulness of EGFR mutation screening in pleural fluid to predict the clinical outcome of gefitinib treated patients with lung cancer. Int J Cancer 119: 2353-2358, 2006.

39. Gow CH, Chang YL, Hsu YC, Tsai MF, Wu CT, Yu CJ, Yang CH, Lee YC, Yang PC and Shih JY: Comparison of epidermal growth factor receptor mutations between primary and corresponding metastatic tumors in tyrosine kinase inhibitor-naive non-smallcell lung cancer. Ann Oncol 20: 696-702, 2009.

40. Kimura H, Fujiwara Y and Sone T: High sensitivity detection of epidermal growth factor receptor mutations in the pleural effusion of non-small cell lung cancer patients. Cancer Sci 97 642-648, 2006.

41. Hung MS, Lin CK, Leu SW, Wu MY, Tsai YH and Yang CT: Epidermal growth factor receptor mutations in cells from non-small cell lung cancer malignant pleural effusions. Chang Gung Med J 29: 373-379, 2006.

42. Tokumo M, Toyooka S and Kiura K: The relationship between epidermal growth factor receptor mutations and clinicopathologic features in non-small cell lung cancers. Clin Cancer Res 11: $1167-1173,2005$

43. Sugio K, Uramoto $H$ and Ono K: Mutations within the tyrosine kinase domain of EGFR gene specifically occur in lung adenocarcinoma patients with a low exposure of tobacco smoking. Br J Cancer 94: 896-903, 2006.

44. Haneda H, Sasaki H and Lindeman N: A correlation between EGFR gene mutation status and bronchioloalveolar carcinoma features in Japanese patients with adenocarcinoma. Jpn J Clin Oncol 36: 69-75, 2006.

45. Huang SF, Liu HP and Li LH, et al: High frequency of epidermal growth factor receptor mutations with complex patterns in non-small cell lung cancers related to gefitinib responsiveness in Taiwan. Clin Cancer Res 10: 8195-8203, 2004.

46. Pao W, Miller V, Zakowski M, Doherty J, Politi K, Sarkaria I, Singh B,Heelan R, Rusch V, Fulton L, Mardis E, Kupfer D, Wilson R, Kris M and Varmus H: EGF receptor gene mutations are common in lung cancers from never smokers and are associated with sensitivity of tumors to gefitinib and erlotinib. Proc Natl Acad Sci USA 101: 13306-13311, 2004.

47. Jian G, Songwen Z, Ling Z, Qinfang D, Jie Z, Liang T and Caicun Z: Prediction of epidermal growth factor receptor mutations in the plasma/pleural effusion to effcacy of gefitinib treatment in advanced non-small cell lung cancer. J Cancer Res Clin Oncol 136: 1341-1347, 2010.

48. Wu SG, Gow CH, Yu CJ, Chang YL, Yang CH, Hsu YC, Shih JY, Lee YC and Yang PC: Frequent epidermal growth factor receptor gene mutations in malignant pleural effusion of lung adenocarcinoma. Eur Respir J 32: 924-930, 2008.

49. Hsieh RK, Lim KH, Kuo HT, Tzen CY and Huang MJ: Female sex and bronchioloalveolar pathologic subtype predict EGFR mutations in non-small cell lung cancer. Chest 128: 317-321, 2005.

50. Shih JY, Gow CH, Yu CJ, Yang CH, Chang YL, Tsai MF, Hsu YC, Chen KY, Su WP and Yang PC: Epidermal growth factor receptor mutations in needle biopsy/aspiration samples predict response to gefitinib therapy and survival of patients with advanced non-small cell lung cancer. Int J Cancer 118: 963-969, 2006.

51. Yi HG, Kim YJ, Han SW, Oh DY, Lee SH, Kim TY, Kim CS, Heo DS and Bang YJ: Epidermal growth factor receptor (EGFR) tyrosine kinase inhibitors (TKIs) are effective for leptomeningeal metastasis from non-small cell lung cancer patients with sensitive EGFR mutation or other predictive factors of good response for EGFR TKI. Lung Cancer 65: 80-84, 2009.
52. de La Motte Rouge T, Valent A, Ambrosetti D, Vielh P and Lacroix L: Clinical and molecular predictors of response to EGFR tyrosine kinase inhibitors in non-small cell lung cancer. Ann Pathol 27: 353-363, 2007.

53. Mitsudomi T and Yatabe Y: Mutations of the epidermal growth factor receptor gene and related genes as determinants of epidermal growth factor receptor tyrosine kinase inhibitor sensitivity in lung cancer. Cancer Sci 98: 1817-1824, 2007.

54. Shepherd FA, Rodrigues Pereira J, Ciuleanu T, et al: Erlotinib in previously treated non-small cell lung cancer. N Engl J Med 353: 123-132, 2005.

55. Love D, White D and Kiroff G: Thoracoscopic talc pleurodesis for malignant pleural effusion. ANZ J Surg 73: 19-22, 2003.

56. Schulze M, Boehie AS, Kurdow R, Dohrmann P and HenneBruns D: Effective treatment of malignant pleural effusion by minimal invasive thoracic surgery: thoracoscopic talc pleurodesis and pleuroperitoneal shunt in 101 patients. Ann Thorac Surg 71: 1809-1812, 2001

57. Viallat JR, Rey F, Astoul P and Boutin C: Thoracoscopic talc pleurodesis for malignant pleural effusions. A review of 360 cases. Chest 110: 1387-1393, 1996.

58. Mitsudomi T, Kosaka T, Endoh H, Horio Y, Hida T, Mori S, Hatooka S, Shinoda M, Takahashi T and Yatabe Y: Mutations of the epidermal growth factor receptor gene predict prolonged survival after gefitinib treatment in patients with non-small cell lung cancer with postoperative recurrence. J Clin Oncol 23: 2513-2520, 2005 .

59. Han SW, Kim TY, Hwang PG, Jeong S, Kim J, Choi IS, Oh DY, Kim JH, Kim DW, Chung DH, Im SA, Kim YT, Lee JS, Heo DS, Bang YJ and Kim NK: Predictive and prognostic impact of epidermal growth factor receptor mutation in non-small cell lung cancer patients treated with gefitinib. J Clin Oncol 23: 2493-2501, 2005.

60. Sonobe M, Manabe T, Wada H and Tanaka F: Mutations in the epidermal growth factor receptor gene are linked to smokingindependent, lung adenocarcinoma. Br J Cancer 93: 355-363, 2005.

61. Liu W, Innocenti F, Chen P, Das S, Cook EH Jr and Ratain MJ: Interethnic difference in the allelic distribution of human epidermal growth factor receptor intron 1 polymorphism. Clin Cancer Res 9: 1009-1012, 2003.

62. Buerger H, Packeisen J and Boecker A: Allelic length of a CA dinucleotide repeat in the egfr gene correlates with the frequency of amplifications of this sequence - first results of an interethnic breast cancer study. J Pathol 203: 545-550, 2004.

63. Shuch B, Mikhail M, Satagopan J, Lee P, Yee H, Chang C, Cordon-Cardo C, Taneja SS and Osman I: Racial disparity of epidermal growth factor receptor expression in prostate cancer. J Clin Oncol 22: 4725-4729, 2004

64. Ekstrand AJ, James CD, Cavenee WK, Seliger B, Pettersson RF and Collins VP: Genes for epidermal growth factor receptor, transforming growth factor alpha and epidermal growth factor and their expression in human gliomas in vivo. Cancer Res 51: 2164-2172, 1991

65. Ekstrand AJ, Sugawa N, James CD and Collins VP: Amplified and rearranged epidermal growth factor receptor genes in human glioblastomas reveal deletions of sequences encoding portions of the N-and/or C-terminal tails. Proc Natl Acad Sci USA 89: 4309-4313, 1992.

66. Kimura H, Fujiwara Y, Sone T, Kunitoh H, Tamura T, Kasahara K and Nishio K: EGFR mutation status in tumor-derived DNA from pleural effusion fluid is a practical basis for predicting the response to gefitinib. Br J Cancer 95: 1390-1395, 2006. 